\title{
Research on the calculation method of ground water heat pump system operating condition
}

\author{
Zishu $\mathrm{Qi}^{1,2,3, a}$, Qiaochu Wang ${ }^{3, \mathrm{~b}}$, Qing Gao ${ }^{2{ }^{*} \mathrm{c}}$ and Zhenhai Gao ${ }^{2}$ \\ ${ }^{1}$ Key Laboratory of Songliao Aquatic Environment of Ministry of Education, Jilin Jianzhu University, \\ Changchun 130118, PR China \\ ${ }^{2}$ State Key Laboratory of Automotive Simulation and Control, Jilin University, Changchun 130025, \\ PR China \\ ${ }^{3}$ School of Municipal and Environment Engineering, Jilin Jianzhu University, Changchun 130118, \\ PR China \\ asenior00685@163.com, ${ }^{b}$ tiger880917@163.com, ${ }^{c}$ gaoqing@jlu.ed.cn \\ ${ }^{*}$ Corresponding author. Fax: +86 431 85094241.E-mail address: gaoqing@jlu.ed.cn (Qing Gao).
}

Keywords: ground water heat pump; fluid; energy consumption; energy efficiency ratio.

\begin{abstract}
In the paper, by studying the ground water heat pump calculation model, the computing platform for heat pump system was established. Through a calculation case, the fluid temperature of ground water heat pump well side and user side, heat pump power consumption and other data were analyzed by entering relevant parameters, which provide an approach for engineering design and operation prediction, and for the thermodynamic analysis of performance of system year by year and prospective study to guide the engineering practice.
\end{abstract}

\section{Introduction}

By using renewable energy, the ground source heat pump system can effectively achieve the building energy-saving. As one of the forms of ground source heat pump system, the ground water heat pump system is widely applied in the areas with rich underground aquifer [1]. Through studying dynamic heat transfer mechanics of the underground pumping well groups, and developing calculation module and calculation platform, this paper is conductive to the application of the water-source heat pump systems on a large scale. It is expected to provide technical support for practical engineering design and operation prediction so as to guide engineering practice by means of further studying the calculation method of ground water heat pump system operation process.

\section{The calculation method}

The ground water heat pump system has developed rapidly in China for the past few years, and its architectural scale and application range become wider and wider. The variation of temperature field in the underground aquifer directly determines the operation effect of water source heat pump air conditioning unit. In addition, the heat transport of aquifer, and researches on engineering operating condition prediction are prerequisites for the sustainable and stable operation under complex pumping operating conditions.

The component devices of water source heat pump system should be simplified for the sake of establishing calculation platform of the ground water heat pump system [2]. Fig.1 shows the system diagram of the ground water heat pump, which includes the ground water heat exchange system as well as the primary water loop system, the secondary water loop system and terminal air-conditioning system of the heat exchanger. The specific equipment components are described in the following diagram. Under winter operating conditions, ground water heat is transferred from the primary water loop system to the secondary water loop system through plate heat exchanger, the secondary water loop fluid flows through the evaporator of heat pump unit heat pump while the terminal air-conditioning system flows through the condenser of heat pump unit to provide heat for the indoors 
of buildings. Under summer operating conditions, the terminal air-conditioning system flows through the evaporator of the heat pump to provide cooling load for the indoors of buildings, the secondary water loop fluid flows through the condenser of heat pump unit to provide heat for the ground through the plate heat exchanger.

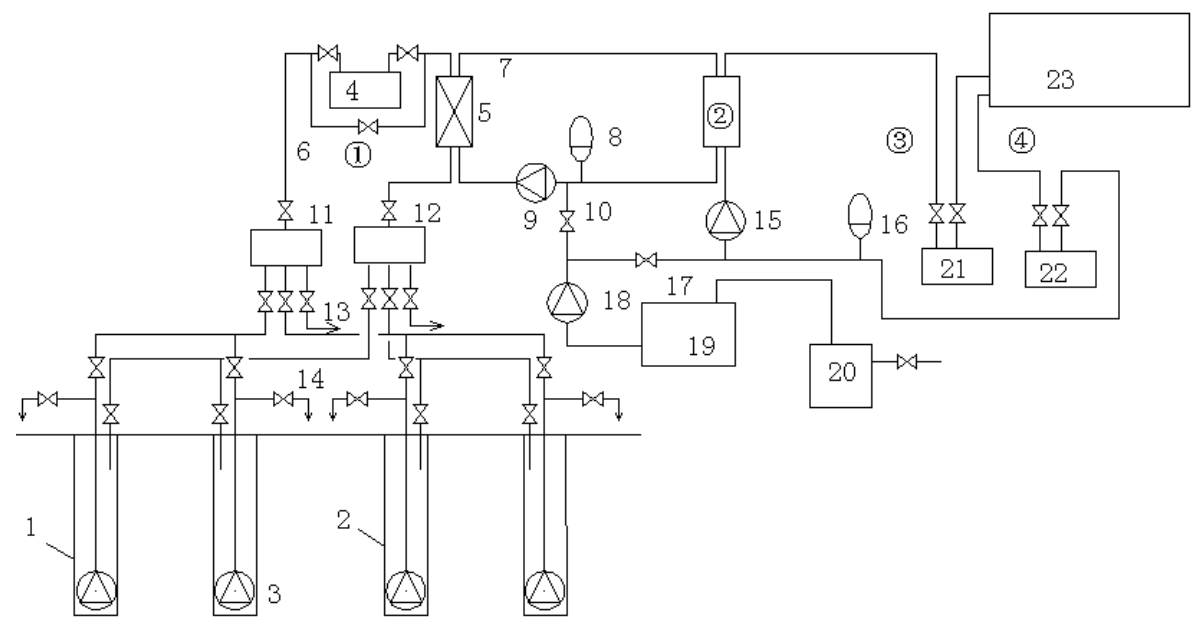

Fig.1 The ground water heat pump system

(1)ground water heat exchanger system (2)water-source heat pump(3)heating medium (cooling medium) pipeline system (4)user air-conditioning system

1- pumping well group 2-recharging well group 3-submersible pump

4-sand eliminator 5-plate heat exchanger 6 - the primary water loop system

7-the secondary water loop system 8-secondary water pipeline constant pressure arrangement

9-secondary water-circulating pump 10-filling water valve of the secondary water loop

11 - conversion valve group 12 - exchanging valving set

13-blow-down and drain valve 14-blow-down and lifting valve

15-heating medium (cooling medium) circulating pump

16-the constant pressure arrangement of heating medium (cooling medium) pipeline system

17-make-up water valve of the heating medium (cooling medium) pipeline system

18-make-up water pump 19-make-up water tank 20-water processing system

21-water-dividing jar 22-water-collecting jar 23-building

The ground water heat pump system can be simplified as shown in Fig.2, with main equipments of plate heat exchanger and heat pump unit. In addition, reservoir balancing also can be added in the system (see Fig.3) to control it by using temperature or temperature difference. When the system load (or the fluid temperature difference of pumping irrigation wells side) is small, reservoir balancing circulating pump can be started rather than pumping irrigation wells pump. When the ground water quality meets the following requirements [3-4] (sand $<1 / 200000$; $\mathrm{PH}$ value of $6.5 \sim 8.5$; Cao $<200 \mathrm{mg} / \mathrm{L}$; salinity <3g/L; $\mathrm{Cl}^{-}<100 \mathrm{mg} / \mathrm{L}, \mathrm{SO}_{4}{ }^{2-}<2200 \mathrm{mg} / \mathrm{L}, \mathrm{Fe}^{2+}<1 \mathrm{mg} / \mathrm{L}, \mathrm{H}_{2} \mathrm{~S}<0.5 \mathrm{mg} / \mathrm{L}$ ), the plate heat exchanger cannot be set and the ground water can directly flow through the evaporator of the heat pump in winter (flow through the condenser of the heat pump in summer ). Taking heat exchange of ground water as an example, this paper discusses the calculation method of the ground water heat pump system operating process.

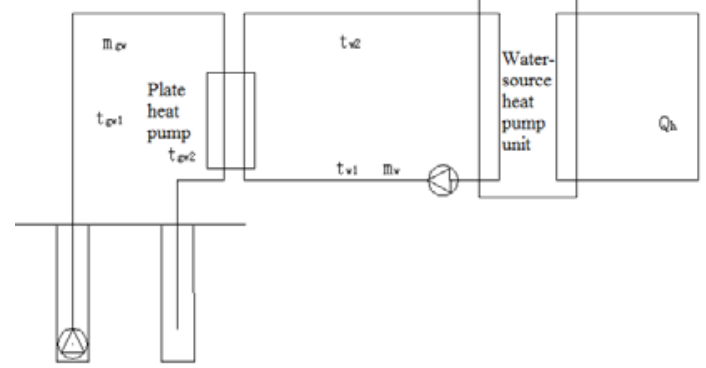

Fig.2 The simplified system

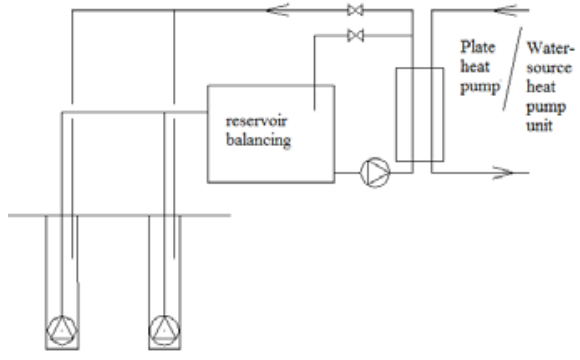

Fig.3 The system with reservoir balancing 


\section{Calculation case}

\section{Calculation procedure}

Taking winter operating condition as the example, the calculation procedure of the ground water heat pump system is drawn as shown in Fig.4. The input parameters include the change with time of the building load ( with average of $477 \mathrm{~kW}$ ), the temperature of $15^{\circ} \mathrm{C}$ for the fluid at the entrance of the evaporator of hot pump unit ( the temperature of pumping well), the temperature of $45^{\circ} \mathrm{C}$ for the supply water of the building air-conditioning system as well as the flux and its performance curve parameters under rated conditions. The return water temperature of the air-conditioning system of the building, the temperature of the recharging well as well as the energy consumption and the energy consumption ratio of the heat pump units can be calculated according to the calculation procedure.

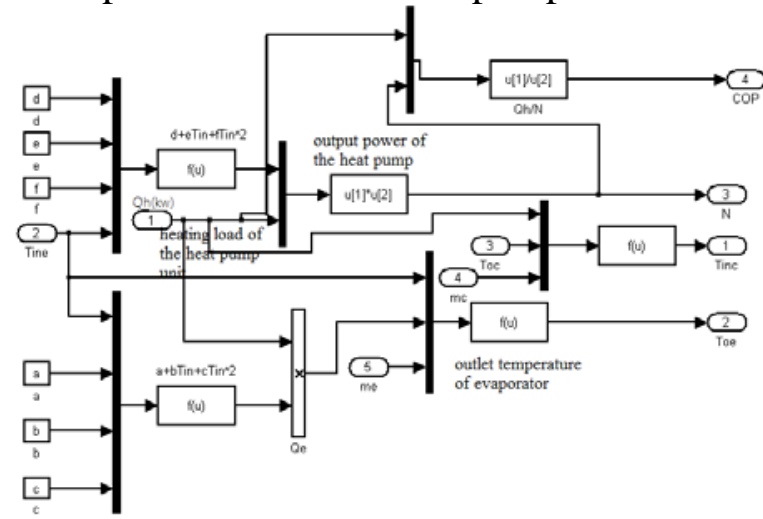

(a) Heat pump unit

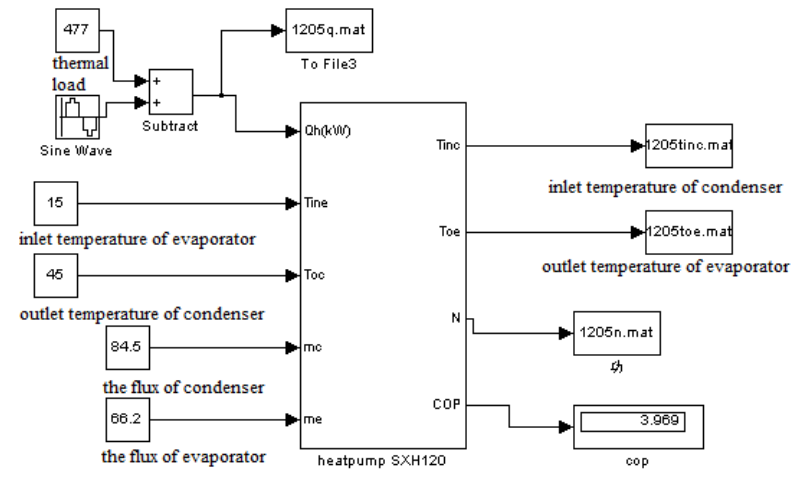

(b) The total program

Fig.4 The calculation procedure

\section{Calculation Results}

Under winter operating conditions, the ground water heat pump system runs for 48 hours. The results of calculation are shown in Fig.5, which are respectively the return water temperature of the air-conditioning system of the building, the temperature of the recharging well and the energy consumption of the heat pump units. Because the change cycle of building load is 24 hours, the return water temperature of the air-conditioning system of the building, the temperature of the recharging well and the energy consumption of the heat pump units change periodically over time as well. It shows some important operation data such as the temperature of the recharging well, the energy consumption and the energy efficiency ratio of the heat pump units under a long-running status through this calculation procedure.

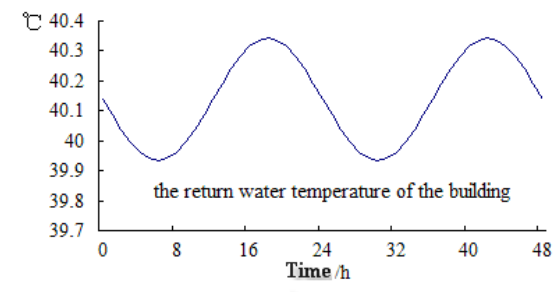

(a) Return water temperature of air-conditioning system (b) Temperature of the recharging well

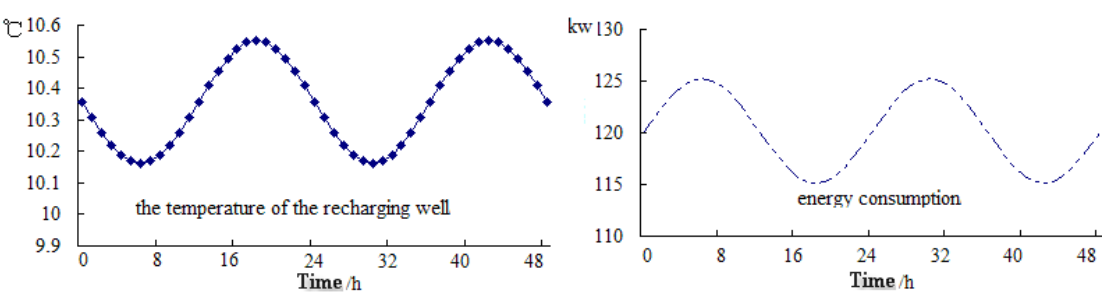

(c) Energy consumption

Fig.5 The calculation results

\section{Conclusions}

Taking the ground water as the heat source, the ground water heat pump system is not affected by ambient temperature with stable operation and obvious energy-saving effect. In order to provide technical support for the ground energy engineering design and operation prediction, this paper establishes a calculation platform of the ground water heat pump system. Through a calculation case, the fluid temperatures of ground water heat pump well side and user side, heat pump power 
consumption and other critical parameters are calculated, which lay a theoretical foundation for the further complex model calculation of the system and the development of other modules.

\section{Acknowledgements}

The authors gratefully acknowledge the financial support from the NSFC (National Natural Science Foundation of China) under the grant No. 51376080, 51076059, 41072198, Key Laboratory of Songliao Aquatic Environment of Ministry of Education, Department of Education of Jilin Province under the grant No.237(2014), Ministry of Housing and Urban-Rural Development of the People's Republic of China, Doctor Scientific Research Staring Foundation of Jilin Jianzhu University.

\section{References}

[1] Long Ni, Zuiliang Ma, Jiaping Feng. The Research Status and Progress of the Ground Water Heat Pump [J]. Building Energy \& Environment, 2004 (2) : 26-31.

[2] Zuiliang Ma, Yue Lv. The Design and Application of the Ground-source Heat Pump [M]. Second Edition, China Machine Press, 2014:102-104.

[3] Xiping Xi, Jihai Xiong, Yunsheng Xie. The Design and Application of Ground Source Heat Pump in Nanchang [J]. Energy Research and Management, 2010.1, P40.

[4] PRC Ministry of Construction. Engineering technology Standard of Ground Source Heat Pump System GB50366 - 2005[M].Beijing, China Publishing House, 2009. 